APPENDIX 



\section{WORLD HERITAGE FOR BUILDING PEACE}

\section{DEL BIANCO Paolo ${ }^{1}$}

1 Paolo Del Bianco, President and Managing Director, COMI-Compagnia Alberghiera Italiana-SpA, Promotor, Founder and President of the Fondazione Romualdo Del Bianco, . President emeritus of the Life Beyond Tourism Movement srl Benefit, Founder and designer of the Museo Fondazione Del Bianco with the restoration of Palazzo Coppini

Dear friends and colleagues, "welcome to Florence", welcome to the Auditorium al Duomo, to the Andrzej Tomaszewski Amphitheatre.

The Fondazione is delighted to host the ICOMOS Committee on the Theory and Philosophy of Conservation and Restoration ... physically once again! You all know what great store the Fondazione sets by this relationship that first saw the light of day at the International Cultural Centre in Krakow on 26 May 2006.

\section{This year, 2021:}

- is the 15th year of the Theory Committee's activity

- the 90th anniversary of the Charter of Athens (1931) which first began the job of establishing the principles of restoration for the conservation of heritage, our shared asset.

This year, 2021, is also:

- the 30th anniversary (14 September 1991) of the start of the Fondazione's activity under the motto "For peace in the world among young people from different countries, through culture - meeting get acquainted understand each other to develop friendship among peoples".

This motto led us in 2018 to formulate our "Heritage for Building Peace" appeal and last year it spawned the "World Heritage for Building Peace Forum".

Moreover, it is also absolutely exceptional that:

- this year, 2021, on 29 and 30 July, Rome hosted the G20 Culture summit:

20 countries meeting to debate economic issues unanimously recognized the importance of culture both from an economic standpoint and for dialogue among peoples. "Culture Unites the World" 


\section{Paolo Del Bianco}

$<$ https://cultura.govit/g20cultura>, thus culture as a contribution to peace in the world which is precisely what the Fondazione Romualdo Del Bianco, over the past 30 years, has resolutely argued and disseminated through its statute ${ }^{1,2}$, and latterly though its movement called Life Beyond Tourism.

Ahead of the event, the Minister for Cultural Affairs Dario Franceschini said:

"Culture is a great tool for dialogue among different peoples, traditions and civilizations and it is a powerful driving force for countries' harmonious and sustainable growth.

[...] in this G20 chaired by Italy, cultural issues are of central importance and they will be a driving force for global recovery after the pandemic".

Winding up the event in response to a journalist who asked him what goal had been achieved, the Minister said: "[...] a sharing of the role of culture as a tool for dialogue and of culture as part of the choices for economic growth over the coming years... From today's debate we have realized that this approach is shared throughout the world."

\section{Statute Fondazione Romualdo Del Bianco 3 novembre 1998}

Art. $2.1 \mathrm{c}$ ) "to promote the establishment in Florence of a Centre for the Development of International Encounters to attract in particular young people and exponents of the cultural, artistic and scientific worlds to foster mutual acquaintance, understanding, friendship and peace between countries and peoples of different nationalities, religions and ethnic groups".

2 Statute Fondazione Romualdo Del Bianco 15 December 2020, Art. 2.1

c) "to promote the establishment in Florence - World Heritage Site - of a Study Centre for the Development of International Encounters to attract in particular young people and exponents of the cultural, artistic and scientific worlds to foster mutual acquaintance, understanding, friendship and peace between countries and peoples of different nationalities, religions and ethnic groups. This Study Centre must facilitate the dissemination, from Florence throughout the world, of "Awareness Centres", the result of research by the Fondazione, cooperating with the "Learning Communities" to foster the transformation of the traveller from "tourist" to "temporary resident". Thus the common approach to heritage must be not only "conservation" and "enhancement" but also "use and enjoyment" for the purpose of carefully developing intepersonal, intercultural, and international relationships to facilitate "encounters", "communication", "knowledge", "conservation" and the "economy" in a framework of respect for our planet and our fellow men; thus these Awareness Centres will search and highlight in travel "the major opportunities that stretch well beyond tourism" in other words 'Life Beyond Tourism-Travel for Dialogue' to make a concrete contribution at the global level to foster the growth of the international community in a framework of peaceful coexistence with respect for the planet Earth that we all share.

Summing up, from Florence, Tuscany, Italy we intend to project a vision of heritage and of contemporary culture as a strategic factor for the construction of peace under the banner of "Heritage for Building Peace"; in particular, we hope and aim to ensure that World Heritage Sites - which attract numerous visitors from different cultural backgrounds - with their management plans may rise to the level of examples and become training centres for enhancing and presenting the "culture", "cultural expressions" and "traditional skills" of individual sites and thus wittingly foster cultural encounters with specific and widespread programmes; in this way they will contribute to dialogue, to knowledge and to respect for diversity, thereby fostering friendship and peace.

The Fondazione will thus be committed to the promotion of the UNESCO Conventions, particularly the Convensions of 1972, World Heritage, of 2003, Intangible Heritage, and 2005, the Promotion and Protection of Diversity of Cultural Expressions and in particular in the search and application of potential synergies amongst them for the international community's growth in a framework of peaceful coexistence.

d) to promote initiatives for sensitising people to the protection and enhancement of the environment in the principle of sustainability under the banner of "Heritage for Planet Earth H4PE". 
The Fondazione is finally seeing the achievement of its great dream of the early '90s:

encounters, communication, knowledge, conservation, the economy, and with these factors, "interpreting and communicating" the culture of sites in order to allow visitors to learn the personality of the place they visit, its skills and know-how', to know and to respect cultural diversity at the global level, for growth in a framework of peaceful coexistence.

With that motto the Fondazione also breathed life into a Movement which organized in March 2020 the above-mentioned "World Forum for Change through Dialogue 2020" with the publication of proceedings over 1,200 pages long.

The event had attracted the confirmed participation of 48 countries from 4 continents, 108 cities, 189 universities and organizations and there were 100 sponsors. Everything was in place, but on 20 February we had to postpone the event due to the serious outbreak of Covid-19 in Italy.

It is worth recalling that the Fondazione was conceived, established and supported by a Florentine hotel company immediately after the fall of the Berlin Wall.

The company, which had been in business for 45 years, had always taken very much to heart its job of providing "hospitality and welcome" in "Florence, Historic Centre, UNESCO World Heritage Site" since 1982.

Months after the fall of the Wall, in 1991, on these precise days, 14 September, hearing the news that a certain Pietro Cannata had taken a hammer to the foot of Michelangelo's David, oddly enough we asked ourselves what difference there might be in the degree of emotion aroused on hearing the news between people in the countries of the former Soviet Union and Soviet Bloc and people in Western countries. Those were also the days of the First Gulf War, closely followed by the SARS epidemic.

The hotel company with its hotel rooms empty due to lack of tourist demand decided to seize the opportunity to host free of charge, and to introduce to Florence, young university students from the countries of the former Soviet Union and Soviet Bloc, those youngsters who had only studied Florence in books in black and white. They were formerly united by the force of politics, but this Florentine hotel company united them with cultural heritage, Florence! Thus we thought of heritage not only in terms of 'conservation' and 'enhancement' but also in terms of its 'use and enjoyment' for social purposes to foster intercultural dialogue, for the international community's growth in a framework of peaceful coexistence.

After the first few years of activity, we set up the Fondazione in 1998 to implement in practical terms the notion that cultural sites, and World Heritage Sites in particular on account of the interest that they arouse in a broad international audience, should rise to the level of "Awareness Centres" for training to dialogue, knowledge and respect for diversity; the public administration and all professional people involved in "welcome and hospitality" should now devote their energies to fostering the evolution of the traveler from "tourist" to "temporary resident" with new forms of commercial offer designed to reduce the overall number of tourists while extending each individual tourist's length of stay. 


\section{Paolo Del Bianco}

You can imagine our joy in hearing the speeches at the G20 Culture summit confirming the validity of what we had foreseen and have been implementing for the past 30 years.

Minister Franceschini stated that: "Culture is a major tool for dialogue among different peoples, traditions and civilizations [...]" Well. we have been practicing and presenting those very concepts at various conferences and in particular in the publication of the above-mentioned Appeal entitled "Building Peace Through Heritage", which we presented at Manama in Bahrain in 2018 in the course of our participation in the 42nd UNESCO WH Committee and subsequently in Baku at the 43rd WH Committee with the updated 2019 edition ${ }^{3}$.

In World Heritage Sites, on account of the large number of visitors they attract from all over the world, "the major opportunities well beyond a tourism based on consumer-driven services" are very obvious in terms of their potential for the international community; thus World Heritage Sites' Management Plans have a chance - though perhaps we may now call it "a duty" - to promote initiatives for interpersonal and intercultural encounters by enacting programmes subscribing to the Movement "well beyond tourism"; thus in the sites we will see a synergy between the 1972, 2003 and 2005 UNESCO Conventions ${ }^{4}$ on the basis of the principle that encounters foster dialogue and knowledge, thus respect for diversity, thereby facilitating peace: so, here we have one more concrete way of safeguarding heritage.

This will prompt worldwide competition for new cultural and commercial offers "well beyond economic globalization", creating opportunities for attention, reflection and the study also of issues regarding our biosphere, our inestimable 'Heritage'.

Since 2006 this ICOMOS Theophilos Committee has imparted a major boost to our research and we can only thank all of its members and its illustrious Presidents and Friends

- Andrzej Tomaszewski, whom we remember with affection and gratitude,

- Wilfried Lipp,

- Bogusław Szmygin.

All of this is now part and parcel of the Fondazione's history and is in our publications, but equally essential to the implementation of this transformation are our recent publications such as the Glossary and the latest edition of "CERTIFICATION for Intercultural Dialogue DTC-LBT H4PE 2021", now in its second edition.

The certification programme has been adopted by $B \mho B$ Hotels Italia - 49 hotels on Italian soil - for a strategic contribution for its own values of Corporate Social Responsibility, in line with the Movement. 


\section{PRACTICAL IMPLEMENTATION : “TALKING SITES”TM}

During the pandemic the Fondazione has continued to promote the practical implementation of its philosophy through the "Life Beyond Tourism Movement-Travel for Dialogue srl Benefit" company it promotes, whose current programmes are also inspired by the ICOMOS 2008 Charter on the interpretation and presentation of cultural heritage sites, also known as the Ename Charter.

In the course of its work, the Movement fosters sites' awareness of the importance of interpreting and communicating their culture, their personality and the richness of their know-how with their local products.

This is achieved via several initiatives: training, consultancy and the DTC LBT-H4PE: 2021 Certification progamme guaranteeing results that can also be gauged by the customer.

We are increasingly learning to recount territories, their outstanding specialities, their hidden gems. This is the goal that we aim to achieve with "Talking Sites"TM, the latest initiative developed by the Life Beyond Tourism - Travel For Dialogue Movement in an effort to join with the various sites in launching a development project for the promotion and enhancement of local identity.

"Talking Sites"TM is implemented directly in a given site and it is also an excellent territorial marketing tool useful for tracking, sharing and expanding an understanding of a territory by all its visitors. Using NFC (Near Field Communication) tags, it is possible to guide the visitor in the discovery of a territory, indicating tours, firms, attractions, activities, events and heritage on the appropriate website; a narrative that can be fully personalised, inspired by all-round enhancement of the site combining the traditional language of photography with web content to create tours and to suggest links within the territory.

Photographic exhibition

Among the practices developed during the pandemic for "Talking Sites"TM we have chosen to "dialogue with images" via a photographic exhibition hosted simultaneously in the universities and institutions in the Fondazione's network. The exhibition introduces the visitor to a guided knowledge of the site through the presentation of details and of cultural expressions with online indepth expansion and interaction on the www.lifebeyondtourism.org portal using NFC technology; this method makes it possible to explore the history, traditions, gastronomy and many other interesting aspects of Florence and Tuscany, producing an all-round narrative of the territory to stimulate curiosity and to allow visitors to plan their future trips in a thoroughly genuine manner.

Entitled "FLORENCE in the WORLD, the WORLD in FLORENCE", this is a five-year programme running from 2021 to 2025, comprising exhibitions in conjunction with universities for an exercise in "awareness of the various sites" and "an exchange of knowledge". The programme is structured in two phases: 


\section{PHASE 1 "Florence in the World"}

16 photographic triptychs (shot by Corinna Del Bianco, member of the TeoPhilos Committee).

The exhibition is currently on display in Azerbaijan, Georgia, Japan, Kyrgyzstan, Italy, Latvia, Lithuania, Poland, Russia, Slovakia and the United Kingdom.

The next few months will see exhibitions being finalized in Armenia, Bosnia-Herzegovina, Ecuador, Egypt, China, the Congo, the Czech Republic, India, Kosovo, Morocco, Kazakhstan, Portugal, Saudi Arabia, Spain, Taiwan, Ukraine and the United Arab Emirates.

\section{PHASE 2 "The World In Florence" (Florence 25-26 November 2022)}

This is the first of the five annual international festivals of the various sites' cultural expressions. The festival sets out to create a circuit of sharing and knowledge of areas in a Life Beyond Tourism vein thanks to photographic contributions being sent to Florence from all over the world. This will give us the opportunity to virtually visit the world through the eyes of residents and to acquire an insightful view of the various sites' culture and of their tangible and intangible heritage: "The Territories Tell Their Story". "Talking Sites ${ }^{\mathrm{TM}}$ ", with panels in the same format as the exhibition in Florence, again with NFC technology. Participation is open to all bodies and institutions at the international level.

Once again the Fondazione is stimulating the younger generations to know, interpret and present their own cultural identity and to gain first-hand training experience under the banner of dialogue, of knowledge and of respect for diversity.

In the course of the five editions from 2021 to 2025 we aim to boost participation in the hope of managing, in the final year, to present roughly 100 territories from the five continents here in Florence.

\section{PARTICIPATION IN 2021:}

Agreement to participate for autumn 2021 has been confirmed so far by Georgia, Azerbaijan, Lithuania, Poland, Russia, Italy, Kosovo, India, Japan, Kazakhstan and Slovacchia.

I would dearly like to see the members of this Committee cooperate in the dissemination of this programme which can make a tangible and rapid contribution to the implementation of a circular synergy between the UNESCO 1972, 2003 and 2005 Conventions ${ }^{5}$, thus forging a strong sensitisation among the younger generations for rethinking the relationship and the balances between travel, a site's culture and intercultural dialogue, all of which are crucial factors for the growth of our international community in a framework of peaceful coexistence and of respect for this planet Earth that we all share.

I would like to conclude by thinking back on our Manifesto in its $2008^{6}$ and $2019^{7}$ editions, on our Appeal of $2019^{8}$ and, with a certain pride, on our Mottos:

5 Learning Communities for intercultural dialogue for territorial development - Slides Book, ISBN 978-88-6039-376-0.

6 World Heritage for Building Peace, Ed. 2019 ISBN 978-88-943894-4-9, pp. 18, 38, 58.

7 Ibidem.

8 World Heritage for Building Peace, Ed. 2019 ISBN 978-88-943894-4-9. 
- 1998 "For peace in the world among young people from different countries, through culture meeting get acquainted understand each other to develop friendship among peoples".

- 2005 "International encounters without competition in a framework of respect for individual identities - A past to get to know together, a common future to build together"

- 2010 "From Florence we help to trigger emotions in young people for reflections of use to the international community" 